\title{
Rebamipide-Promoted Restoration of Gastric Mucosal Sonic Hedgehog Expression after Early Helicobacter Pylori Eradication
}

\author{
Toshihiro Nishizawa Hidekazu Suzuki Izumi Nakagawa Yuriko Minegishi \\ Tatsuhiro Masaoka Eisuke Iwasaki Toshifumi Hibi \\ Division of Gastroenterology and Hepatology, Department of Internal Medicine, Keio University School of \\ Medicine, Tokyo, Japan
}

\section{Dear Sir,}

Sonic hedgehog (Shh) is a soluble signal that is secreted in concentration gradients through a tissue and regulates epithelial cell differentiation. Disturbances of epithelial cell differentiation induced by Helicobacter pylori-associated gastritis in Mongolian gerbils are correlated closely with changes in Shh expression [1]. We previously reported that suppressed Shh expression in the gastric mucosa by H. $p y$ lori infection was significantly restored following eradication of the bacterium, in both humans [2] and Mongolian gerbils [3]. H. pylori-associated deregulation of Shh expression was reversible after $H$. $p y$ lori eradication. The restoration of Shh expression was confirmed by immunohistochemistry, mRNA expression and in situ hybridization in Mongolian gerbils [3]. Earlier eradication promoted better restoration of the Shh expression in the gastric mucosa of the Mongolian gerbil [3].

Rebamipide, 2-(4-chlorobenzoylamino)-3-[2-(1H)-quinolinon-4-yl]propionic acid, has been reported to exert a preventive effect on drug-induced gastric ulcer formation by inhibiting neutrophil activation [4]. The drug has oxygen radical scavenging effects and stimulates prostaglandin generation in the gastric mucosa. Terano et al. [5] recently reported that in a randomized, double-blind, placebo-con- trolled trial, rebamipide significantly promoted gastric ulcer healing following eradication. Here, the effect of rebamipide on the restoration of Shh expression after $H$. pylori eradication was assessed.

The data of gerbils with chow diet used in this study were previously examined and partially reported, in terms of eradication and Shh regeneration [3]. The experimental design is shown in figure 1 . In experiment I, 32 male Mongolian gerbils (MGS/Sea) were divided into 2 groups. Gerbils assigned to the $H$. pylori-infected group (I group, $\mathrm{n}=16$ ) and the $H$. pyloriinfected group administered eradication therapy ( $\mathrm{I}+\mathrm{E}$ group, $\mathrm{n}=16$ ) were administered $H$. pylori suspensions at the age of 5 weeks. For $H$. pylori eradication, lansoprazole $(10 \mathrm{mg} / \mathrm{kg})$, amoxicillin $(3 \mathrm{mg} / \mathrm{kg})$ and clarithromycin $(30 \mathrm{mg} / \mathrm{kg}$; in $0.5 \% \mathrm{wt} / \mathrm{wt}$ carboxymethyl cellulose sodium salt) were administered intragastrically twice daily on 2 successive days 12 weeks after bacterial inoculation [3]. After eradication, the animals in both the I group and the $\mathrm{I}+\mathrm{E}$ group were further subdivided into the chow diet and rebamipide-containing diet groups $(0.25 \%)$ [6]. Ten weeks after eradication, the gerbils were examined under ether anesthesia. In experiment II, eradication was carried out 24 weeks after inoculation, and in experiment III, 48 weeks after inoculation. Myeloperoxidase (MPO) activity, as an index of tissue-associated neutrophil accumulation, was determined by a modification of the method of Grisham et al. [3], as described previously. Acute inflammation (neutrophil infiltration), chronic inflammation (mononuclear cell infiltration) and glandular atrophy were graded on a scale from 0 (absent/normal) to 3 (maximal intensity) in accordance with the updated Sydney System. The histopathological scores were evaluated in the mid-portion by a single investigator who was blinded to experimental protocols [3]. The immunohistochemistry of Shh was performed using a goat polyclonal anti-Shh antibody (N-19, 1:200; Santa Cruz Biotechnology, Santa Cruz, Calif., USA) directed against the Shh precursor protein [1]. The horizontal length $(\mu \mathrm{m})$ of the mucosal region showing Shh expression was measured $[1,3]$. All gerbils of the $H$. pylori-infected group were confirmed as $H$. pylori positive, and all gerbils of $H$. pylori-eradicated groups were confirmed as $H$. pylori negative by a microaerobic bacterial culture [3].

Only among gerbils with $H$. pylori eradication 12 weeks after the bacterial inoculation, cohorts assigned to rebamipide-containing diet showed a significant reduction in MPO activity, scores of acute inflammation and atrophy, as compared with those assigned to chow diet $(p<0.05$;

\section{KARGER}

Fax +4161306 1234 E-Mail karger@karger.ch www.karger.com
Hidekazu Suzuki, MD, PhD

Department of Internal Medicine

Keio University School of Medicine

35 Shinanomachi, Shinjuku-ku, Tokyo 160-8582 (Japan)

Tel. +81 35363 3914, Fax +81 35363 3967, E-Mail hsuzuki@sc.itc.keio.ac.jp 
Fig. 1. Experimental design. Mongolian gerbils were inoculated with $H$. pylori at the age of 5 weeks. H. pylori eradication therapy was administered at 12, 24 or 48 weeks after inoculation. After the eradication treatment, the $H$. pylori-infected gerbils (I group) and the H. pylori-infected gerbils administered eradication therapy (I+E group) were further subdivided into the chow diet group and the rebamipidecontaining diet group. The gerbils were examined at 10 weeks after the eradication therapy. $\boldsymbol{\nabla}=$ H. pylori inoculation; $\nabla=$ eradication; $\mathrm{S}=$ sacrifice.

Fig. 2. Horizontal length of the areas showing Shh expression in the group administered eradication therapy at 24 weeks. About $50 \%$ of the animals in this group exhibited HPGs. In gerbils without HPGs, cohorts assigned to the rebamipide-containing diet showed a significant increase in the horizontal mucosal length of Shh expression, as compared with those assigned to chow. In gerbils with HPGs, no significant changes in the length of Shh expression were observed in cohorts assigned to rebamipide-containing diet as compared with those assigned to chow diet. ${ }^{*} \mathrm{p}<0.05$ versus the chow diet group.

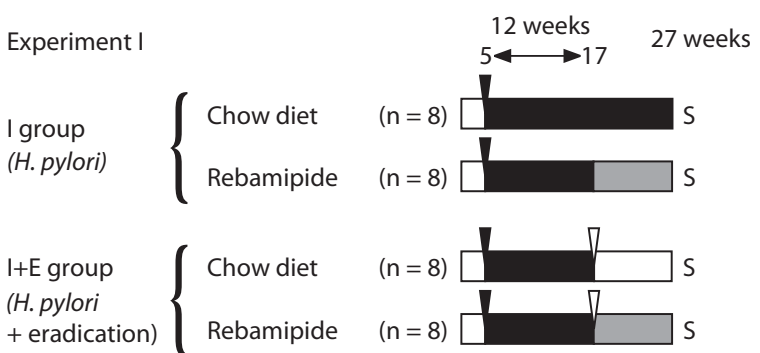

Experiment II

I group
(H. pylori) $\quad\left\{\begin{array}{l}\text { Chow diet } \\ \text { Rebamipide }\end{array}\right.$

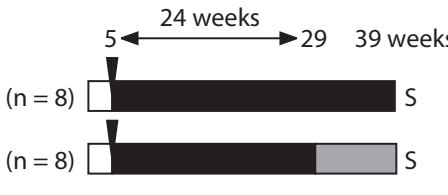

$\begin{aligned} & \text { I+E group } \\ & \text { (H. pylori } \\ & \text { + eradication) }\end{aligned}$$\left\{\begin{array}{l}\text { Chow diet } \\ \text { Rebamipide }\end{array}\right.$

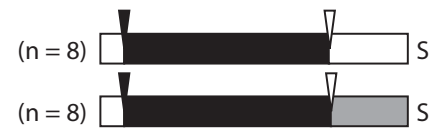

Experiment III

$\begin{aligned} & \text { I group } \\ & \text { (H. pylori) }\end{aligned}$
$\begin{aligned} & \text { I+E group } \\ & \text { (H. pylori } \\ & \text { + eradication) }\end{aligned}$$\left\{\begin{array}{l}\text { Chow diet } \\ \text { Rebamipide }\end{array}\right.$
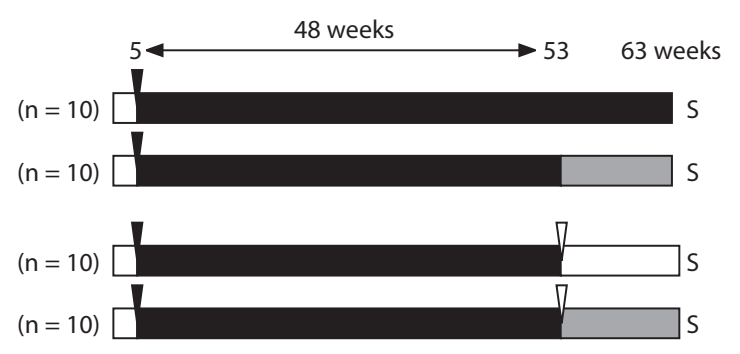

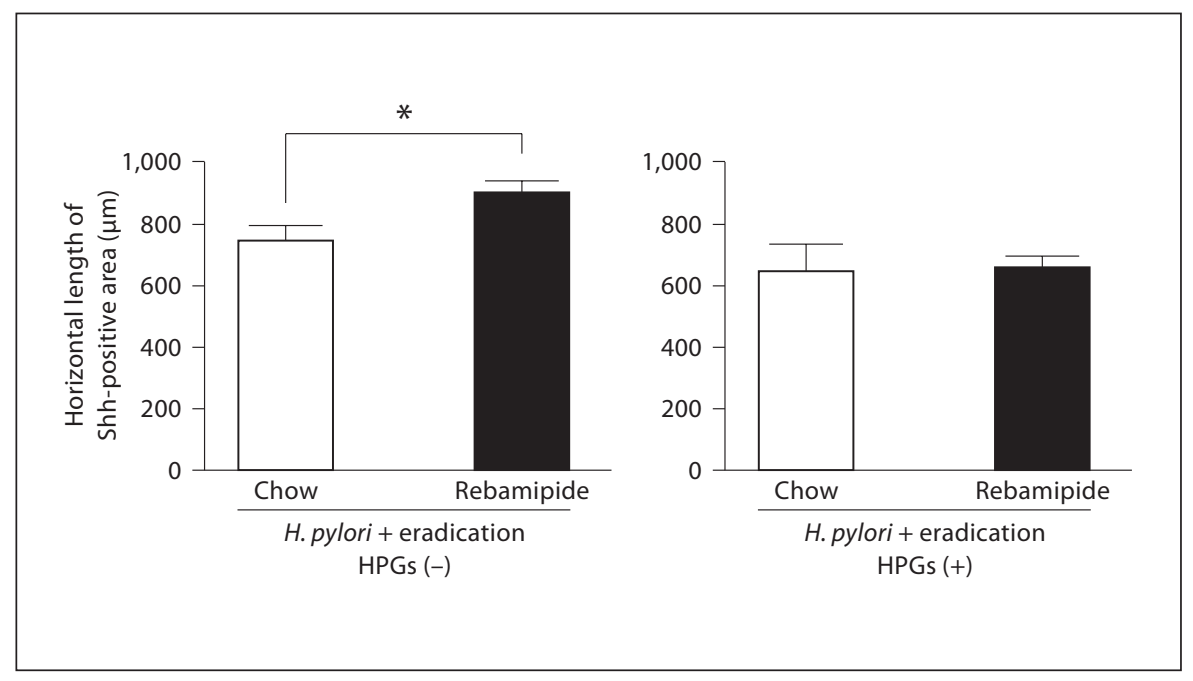


Table 1. MPO activity in the stomach, acute and chronic inflammation scores, atrophy score, and the horizontal mucosal length of Shh expression in the stomach

\begin{tabular}{|c|c|c|c|c|c|c|}
\hline & & $\begin{array}{l}\text { MPO activity } \\
\mathrm{mU} / \mathrm{mg} \\
\text { protein }\end{array}$ & $\begin{array}{l}\text { Acute } \\
\text { inflammation } \\
\text { score }\end{array}$ & $\begin{array}{l}\text { Chronic } \\
\text { inflammation } \\
\text { score }\end{array}$ & $\begin{array}{l}\text { Atrophy } \\
\text { score }\end{array}$ & $\begin{array}{l}\text { Horizontal mucosal } \\
\text { length of Shh } \\
\text { expression, } \mu \mathrm{m}\end{array}$ \\
\hline \multicolumn{7}{|l|}{ Experiment I/12 weeks } \\
\hline H. pylori & $\begin{array}{l}\text { Chow } \\
\text { Rebamipide }\end{array}$ & $\begin{array}{l}4.80 \pm 1.19 \\
4.94 \pm 1.68\end{array}$ & $\begin{array}{l}2.46 \pm 0.74 \\
2.41 \pm 0.56\end{array}$ & $\begin{array}{l}2.28 \pm 0.59 \\
2.28 \pm 0.53\end{array}$ & $\begin{array}{l}2.12 \pm 0.71 \\
2.17 \pm 0.56\end{array}$ & $\begin{array}{l}2,150 \pm 760 \\
2,220 \pm 770\end{array}$ \\
\hline \multirow[t]{2}{*}{ H. pylori + eradication } & Chow & $1.02 \pm 0.26$ & $1.00 \pm 0.47$ & $1.16 \pm 0.41$ & $1.00 \pm 0.64$ & $6,890 \pm 1,420$ \\
\hline & Rebamipide & $0.65 \pm 0.14^{*}$ & $0.54 \pm 0.31^{*}$ & $0.62 \pm 0.41$ & $0.37 \pm 0.42^{*}$ & $8,490 \pm 1,240^{*}$ \\
\hline \multicolumn{7}{|l|}{ Experiment II/24 weeks } \\
\hline \multirow[t]{2}{*}{ H. pylori } & Chow & $4.20 \pm 1.03$ & $2.17 \pm 0.44$ & $1.95 \pm 0.30$ & $2.32 \pm 0.37$ & $2,300 \pm 820$ \\
\hline & Rebamipide & $3.78 \pm 1.31$ & $1.79 \pm 0.62$ & $2.05 \pm 0.84$ & $2.12 \pm 0.80$ & $2,630 \pm 890$ \\
\hline \multirow[t]{2}{*}{ H. pylori + eradication } & Chow & $3.07 \pm 0.96$ & $1.04 \pm 0.52$ & $1.22 \pm 0.50$ & $1.56 \pm 0.76$ & $6,470 \pm 1,060$ \\
\hline & Rebamipide & $2.72 \pm 0.79$ & $0.70 \pm 0.41$ & $0.71 \pm 0.40$ & $0.99 \pm 0.64$ & $7,540 \pm 1,410$ \\
\hline \multicolumn{7}{|l|}{ Experiment III/48 weeks } \\
\hline \multirow[t]{2}{*}{ H. pylori } & Chow & $2.69 \pm 1.33$ & $1.55 \pm 0.40$ & $2.43 \pm 0.57$ & $2.40 \pm 0.36$ & $1,690 \pm 1,550$ \\
\hline & Rebamipide & $2.27 \pm 0.95$ & $1.41 \pm 0.46$ & $2.19 \pm 0.54$ & $2.18 \pm 0.44$ & $2,170 \pm 1,630$ \\
\hline \multirow[t]{2}{*}{ H. pylori + eradication } & Chow & $1.66 \pm 0.34$ & $0.66 \pm 0.19$ & $1.00 \pm 0.37$ & $1.86 \pm 0.63$ & $4,940 \pm 2,890$ \\
\hline & Rebamipide & $1.52 \pm 0.79$ & $0.44 \pm 0.23$ & $0.81 \pm 0.42$ & $1.77 \pm 0.73$ & $4,510 \pm 2,010$ \\
\hline
\end{tabular}

Among the gerbils administered $H$. pylori eradication therapy 12 weeks after the bacterial inoculation, the rebamipide-containing diet group showed a significant reduction in MPO activity, acute inflammation scores and atrophy score, as well as a significant increase in the horizontal mucosal length of Shh expression as compared with the chow diet group.

${ }^{*} \mathrm{p}<0.05$ versus the chow diet group.

table 1). Furthermore, only among the gerbils with $H$. pylori eradication 12 weeks after bacterial inoculation, cohorts assigned to the rebamipide-containing diet showed a significant increase in the horizontal mucosal length of Shh expression, as compared with those assigned to chow diet $(\mathrm{p}<0.05$; table 1$)$. Since rebamipide stimulates the production of prostaglandins and epidermal growth factor, these effects may promote the restoration of Shh expression and the regeneration of atrophic mucosa. In the present study, $50 \%$ of the animals in the group administered eradication at 24 weeks exhibited heterotopic proliferative glands (HPGs), which are associated with severe gastritis. In gerbils without HPGs administered eradication therapy at 24 weeks, cohorts assigned to the rebamipide-containing diet showed a significant increase in the horizontal mucosal length of Shh expression, as compared with those assigned to chow. In gerbils with HPGs, no significant changes in the length of Shh expression were observed in cohorts assigned to rebamipide-containing diet as compared with those assigned to chow diet (fig. 2). All gerbils in the group administered eradication at 48 weeks exhibited HPGs; the effect of rebamipide was not observed. Ikeno et al. [7] reported a similar natural history of $H$. pylori infection in Mongolian gerbils where acute inflammation seemed to decrease after 12 weeks, whereas the chronic inflammation score and metaplastic change appeared to be constant until 52 weeks after the inoculation. According to the report on gerbils by Cao et al. [8], the area occupied by HPGs remained until 25 weeks after eradication, and the HPGs are considered to be less reversible. Also in humans, loss of mucosal Shh expression in $H$. pylori-associated atrophic gastritis responds to eradication and its reversibility depends on the severity of atrophic gastritis and the presence of incomplete intestinal metaplasia prior to H. pylori eradication [9]. Earlier eradication than the development of HPGs would be desirable for complete resolution of H. pylori-associated gastritis.

The MPO activity and inflammation and atrophy scores in the $H$. pylori-infected gerbils were not decreased by treatment with rebamipide alone without eradication. There is one possible explanation, namely that the inflammation in $\mathrm{H}$. pylo$r i$-infected gastric mucosa is so severe that administration of rebamipide alone might not be sufficient to attenuate neutrophil infiltration. The present experimental data suggest the possibility of rebamipide as a suitable agent for administration after H. pylori eradication, with the aim of alleviating gastric inflammation and promoting the reversal of gastric atrophy.

In conclusion, rebamipide treatment after early $H$. pylori eradication significantly promoted the restoration of Shh expression and the regeneration of atrophic mucosa.

\section{Acknowledgements}

The preliminary results of this manuscript were presented at the 1st meeting of Inflammation Conference in Alimentary Tract (ICAT) held September 16, 2006 in Tokyo and awarded 1st ICAT award. 


\section{References}

1 Suzuki H, Minegishi Y, Nomoto Y, Ota T, Masaoka T, van den Brink GR, et al: Downregulation of a morphogen (sonic hedgehog) gradient in the gastric epithelium of Helicobacter pylori-infected Mongolian gerbils. J Pathol 2005;206:186-197.

2 Nishizawa T, Suzuki H, Masaoka T, Minegishi Y, Iwasahi E, Hibi T: Helicobacter pylori eradication restored sonic hedgehog expression in the stomach. Hepatogastroenterology 2007;54:697-700.

- 3 Nishizawa T, Suzuki H, Nakagawa I, Minegishi Y, Masaoka T, Iwsaki E, et al: Early $\mathrm{He}$ licobacter pylori eradication restores sonic hedgehog expression in the gastric mucosa. Digestion 2009;79:99-108.
4 Suzuki M, Miura S, Mori M, Kai A, Suzuki $\mathrm{H}$, Fukumura D, et al: Rebamipide, a novel antiulcer agent, attenuates Helicobacter pylori induced gastric mucosal cell injury associated with neutrophil derived oxidants. Gut 1994;35:1375-1378.

5 Terano A, Arakawa T, Sugiyama T, Suzuki H Joh T, Yoshikawa T, et al: Rebamipide, a gastro-protective and anti-inflammatory drug, promotes gastric ulcer healing following eradication therapy for Helicobacter pylori in a Japanese population: a randomized, double-blind, placebo-controlled trial. J Gastroenterol 2007;42:690-693.

6 Suzuki H, Mori M, Kai A, Suzuki M, Suematsu M, Miura S, et al: Effect of rebamipide on $H$. pylori-associated gastric mucosal injury in Mongolian gerbils. Dig Dis Sci 1998; 43(suppl 9):181S-187S.
7 Ikeno T, Ota H, Sugiyama A, Ishida K, Katsuyama T, Genta RM, et al: Helicobacter pylori-induced chronic active gastritis, intestinal metaplasia, and gastric ulcer in Mongolian gerbils. Am J Gastroenterol 1999;154: 951-960.

8 Cao X, Tsukamoto T, Nozaki K, Shimizu N, Mizoshita T, Kumagai T, et al: Eradication of Helicobacter pylori induces apoptosis and inhibits proliferation of heterotopic proliferative glands in infected Mongolian gerbils. Cancer Sci 2004;95:872-877.

9 Shiotani A, Uedo N, Iishi H, Tatsuta M, Ishiguro S, Nakae Y, et al: Re-expression of sonic hedgehog and reduction of CDX2 after Helicobacter pylori eradication prior to incomplete intestinal metaplasia. Int J Cancer 2007;121:1182-1189. 